\title{
Allergic Contact Dermatitis Induced by Textile Necklace
}

\author{
Uffe Nygaard $^{\mathrm{a}}$ Henrik Højgrav Kralund $^{\mathrm{b}}$ Mette Sommerlund $^{\mathrm{a}}$ \\ ${ }^{a}$ Department of Dermatology and Venerology, Aarhus University Hospital, University of \\ Aarhus, Aarhus, and ${ }^{b}$ Department of Dermatology and Allergy Centre, Odense University \\ Hospital, University of Southern Denmark, Odense, Denmark
}

\section{Key Words}

Allergic contact dermatitis · Textile dermatitis · Disperse dyes · Disperse Yellow 3 - Disperse Orange 1

\begin{abstract}
Allergic contact dermatitis to textile dyes is considered to be a rare phenomenon. A recent review reported a prevalence of contact allergy to disperse dyes between 0.4 and $6.7 \%$. The relevance of positive patch testing was not reported in all studies. Textile dye allergy is easily overlooked and is furthermore challenging to investigate as textile dyes are not labelled on clothing. In this report, we present a case of allergic contact dermatitis to a textile necklace. The patch test showed strong reactions to the necklace and the azo dyes Disperse Orange 1 and Disperse Yellow 3. Despite the European legislation and the reduced use of disperse dyes in Third World countries, disperse azo dyes still induce new cases of allergic contact dermatitis.

(C) 2013 S. Karger AG, Basel
\end{abstract}

\section{Introduction}

Azo dyes, the most frequently applied disperse dyes, are well-known inducers of allergic contact dermatitis and are used as colorants of synthetic fibers [1]. Cross-reactivity between azo dyes and p-phenylenediamine (PPD) is common [2, 3]. Allergic contact dermatitis from either Disperse Yellow 3 (DY3) or Disperse Orange 1 (D01) is thought to derive from direct skin exposure to dye or from cross-sensitization of other para-amino compounds, most frequently PPD. Previously, Disperse Blue 106 and 124 were the most common allergens among textile dyes [4], but recent studies suggest D01 and DY3 have surmounted them [5, 
6]. Allergic contact dermatitis to textiles can be seen upon direct contact to clothing or textile accessories.

\section{Case Report}

A 45-year-old woman with known chronic urticaria was referred to our department for further investigation of contact allergy to textiles. She had previously experienced 2 episodes of localized skin reactions upon direct contact with textiles. In 2004, she developed a skin reaction to an orange lace on a black t-shirt and in 2012, wearing a yellow/orange textile necklace resulted in an exuding dermatitis (fig. 1). Questioning revealed that the patient previously had a henna tattoo (in 2005) and frequent hair bleaching, neither resulting in dermatitis, urticaria, or angioedema. Clinical examination disclosed several unremarkable permanent tattoos. She had previously been patch-tested with the TRUE Test ${ }^{\circledR}$ (Vitaflo, Denmark), and pieces of the necklace showed a 3+ reaction on days 2 and 7 to both PPD and the necklace. When referred to our department, we performed a patch test with the European Standard Series TRUE Test ${ }^{\circledR}$ (Vitaflo), supplemented with the azo dyes DY3, D01, Disperse Yellow 9 (DY9), Acid Yellow 61, and Direct Orange 34 (Chemotechnique Diagnostics, Sweden). The patch test confirmed +3 PPD , +3 D01, +3 DY3, and +2 DY9 (table 1). The necklace was not available for additional testing or chemical analyses. Patch testing provoked recall dermatitis on the neck. The patient was instructed to avoid both hair dyeing and henna tattoos and to use pure cotton or white clothing.

\section{Discussion}

Disperse dye regulations in Western countries are quite meticulous and, albeit rare, azo dyes are still detected in garments made both in and outside the EU [7]. Contact allergy to disperse azo dyes is mainly caused by nonoccupational exposure to textiles, and this type of allergy is likely underdiagnosed. This may be due to an underreporting by patients, weak skin reactions, and difficulty in associating contact dermatitis with relevant exposure. Even when allergy is suspected, identifying the allergens is challenging because clothing labels have no declaration on textile dyes and finishers, and colors are often a mixture of several individual disperse dyes. In this case, we identified 3 important disperse azo dyes as the possible cause of allergic contact dermatitis. It has been hypothesized that both DY3 and D01 are metabolized on the skin by commensal bacteria, and the metabolites are thought to penetrate the skin and therefore becoming major sensitizers. The metabolites paminodiphenylamine and 2-amino-p-cresol may cross-react with PPD [8]; however, in this case, PPD allergy may also stem from an earlier exposure to Henna.

\section{Conclusion}

The present case demonstrates that textile allergy from azo dyes is still a cause of allergic contact dermatitis; hence it is important to also consider the possibility of textile allergy and to test the patients' own products (if possible). Careful patient information on how to avoid exposure to disperse azo dyes is of utmost importance (to avoid a recurrence). As azo dyes are currently used to create almost every nuance in synthetic textiles, it is not sufficient 
Nygaard et al.: Allergic Contact Dermatitis Induced by Textile Necklace

to only avoid yellow/orange/black synthetic fabrics; especially colored lingerie of synthetic material, worn directly on the skin, may cause dermatitis.

\section{References}

1 Le Coz C-J: Clothing; in Johansen JD, Frosch PJ, Lepoittevin J-P (eds): Contact Dermatitis, ed 5. Berlin, Heidelberg, 2011, pp 793-819.

2 LaBerge L, Pratt M, Fong B, Gavigan G: A 10-year review of p-phenylenediamine allergy and related paraamino compounds at the Ottawa Patch Test Clinic. Dermatitis 2011;22:332-334.

-3 Goon AT, Gilmour NJ, Basketter DA, White IR, Rycroft RJ, McFadden JP: High frequency of simultaneous sensitivity to Disperse Orange 3 in patients with positive patch tests to para-phenylenediamine. Contact Dermatitis 2003;48:248-250.

4 Lazarov A: Textile dermatitis in patients with contact sensitization in Israel: a 4-year prospective study. J Eur Acad Dermatol Venereol 2004;18:531-537.

5 Ryberg K, Isaksson M, Gruvberger B, Hindsen M, Zimerson E, Bruze Ml: Contact allergy to textile dyes in southern Sweden. Contact Dermatitis 2006;54:313-321.

-6 Malinauskiene L, Bruze M, Ryberg K, Zimerson E, Isaksson M: Contact allergy from disperse dyes in textiles: a review. Contact Dermatitis 2013;68:65-75.

-7 Malinauskiene L, Zimerson E, Bruze M, Ryberg K, Isaksson M: Are allergenic disperse dyes used for dyeing textiles? Contact Dermatitis 2012;67:141-148.

8 Malinauskiene L, Zimerson E, Bruze M, Ryberg K, Isaksson M: Patch testing with the textile dyes Disperse Orange 1 and Disperse Yellow 3 and some of their potential metabolites, and simultaneous reactions to para-amino compounds. Contact Dermatitis 2012;67:130-140.

Table 1. Patch test results

\begin{tabular}{lll}
\hline Agent & Day 3 & Day 7 \\
\hline PPD & +++ & +++ \\
D01 & +++ & +++ \\
DY3 & +++ & +++ \\
DY9 & ++ & ++ \\
Acid Yellow 61 & $+/-$ & $+/-$ \\
Direct Orange 34 & $+/-$ & $+/-$ \\
\hline
\end{tabular}

$+++=$ Extreme reaction; ++ = Strong positive; + = Weak positive; $+/-=$ Equivocal/uncertain. Acid yellow 61 and direct orange 34 showed only doubtful positive reactions. 
Nygaard et al:: Allergic Contact Dermatitis Induced by Textile Necklace

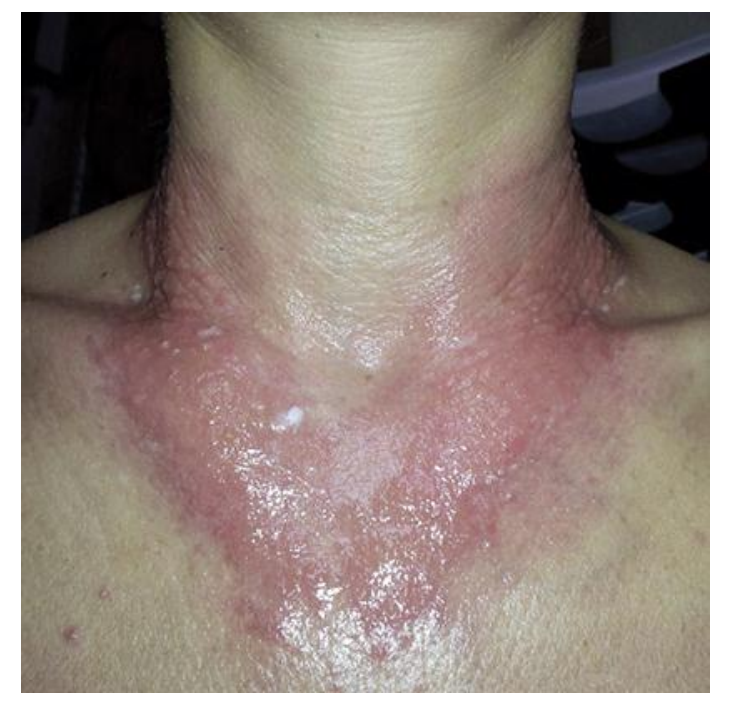

Fig. 1. Severe erythema, edema, and vesicular dermatitis after wearing a textile necklace. 